\title{
Advances in Neuroscience and the Biological and Toxin Weapons Convention
}

\begin{abstract}
Malcolm Dando
Wellcome Trust Dual-Use Bioethics Group, Bradford Disarmament Research Centre, Department of Peace Studies, University of Bradford, Bradford BD7 1DP, UK

Correspondence should be addressed to Malcolm Dando, mrdando@bradford.ac.uk

Received 1 June 2010; Accepted 25 August 2010

Academic Editor: Maxim Golovkin

Copyright ( $\odot 2011$ Malcolm Dando. This is an open access article distributed under the Creative Commons Attribution License, which permits unrestricted use, distribution, and reproduction in any medium, provided the original work is properly cited.

This paper investigates the potential threat to the prohibition of the hostile misuse of the life sciences embodied in the Biological and Toxin Weapons Convention from the rapid advances in the field of neuroscience. The paper describes how the implications of advances in science and technology are considered at the Five Year Review Conferences of the Convention and how State Parties have developed their appreciations since the First Review Conference in 1980. The ongoing advances in neurosciences are then assessed and their implications for the Convention examined. It is concluded that State Parties should consider a much more regular and systematic review system for such relevant advances in science and technology when they meet at the Seventh Review Conference in late 2011, and that neuroscientists should be much more informed and engaged in these processes of protecting their work from malign misuse.
\end{abstract}

\section{Introduction}

Article I of the Biological and Toxin Weapons Convention (BTWC) reads [1]:

"Each State Party to this Convention undertakes never in any circumstances to develop, produce, stockpile or otherwise acquire or retain:

(1) Microbial or other biological agents, or toxins whatever their origin or method of production, of types and in quantities that have no justification for prophylactic, protective or other peaceful purposes,

(2) Weapons, equipment or means of delivery designed to use such agents or toxins for hostile purposes or in armed conflict."

The sweeping prohibition of the nonpeaceful uses of agents or toxins set out in Article I.1 has become known as the General Purpose Criterion, and the statement "never in any circumstances" indicates that the negotiators in the early 1970s intended the prohibition to apply then, now, and into the future. The wording of Article I.2 "for hostile purposes or in armed conflict" also indicates the wide scope that the negotiators had in mind for the prohibition.
However, the BTWC also states in Article XII that:

"Five years after the entry into force of this Convention... a conference of States Parties to the Convention shall be held at Geneva, Switzerland, to review the operation of the Convention, with a view to assuring that the purposes of the preamble and the provisions of the Convention.... are being realized. Such review shall take into account any new scientific and technological developments relevant to the Convention.”

The last sentence of Article XII may perhaps be seen as an indication that already, in the early 1970s, the negotiators had a concern that very rapid advances were being made in the life sciences and that these might lead to the production of new materials, technologies, or knowledge which would need to be taken into account in order to maintain and strengthen the prohibition.

As it turned out, at the First Review Conference in 1980 the States Parties' conclusion in their Final Declaration was relatively sanguine on this point. Under Article I there were just two paragraphs stating [2]: 
"The conference notes the importance of Article I as the article which defines the scope of the Convention and reaffirms its support for the provisions of this Article.

The Conference believes that Article I has proved sufficiently comprehensive to have covered recent scientific and technological developments relevant to the Convention."

Additionally, under Article XII, the Final Declaration stated:

\begin{abstract}
"The Conference... believes that such conferences constitute an effective method of reviewing the operation of the Convention with a view of assuring that its purposes and provisions are being realized, in particular with respect to any new scientific and technological developments relevant to the Convention."
\end{abstract}

The Preparatory Committee for the Review Conference had requested the Depositary Governments - the USSR, the USA, and the UK-to prepare a background paper on new scientific and technological developments relevant to the Convention and to provide the paper to all the States Parties prior to the Review Conference and had invited other States Parties to do so if they wished. Clearly, this mechanism was found satisfactory at the First Review Conference and, although the joint paper by the Depositary States was not repeated, the mechanism developed into a means by which any State Party to the Convention could contribute to the background paper prepared for the following five-yearly Review Conferences. As shown in Table 1, though not many States Parties have chosen to make such contributions, a small number have regularly done so.

\section{Scientific and Technological Developments Relevant to the Convention}

The sanguine attitude of the First Review Conference towards scientific and technological developments relevant to the BTWC did not last long. Indeed, even at the time of the First Review Conference a contribution by Sweden had noted the considerable recent progress in "cell-genetics and biotechnology, particularly in the areas of gene and enzyme technology." It went on to point out the implications of the new genetic techniques that, it suggested:

“... imply a potential to change existing potential BW-agents, for example, in order to increase their ability to survive in different environments. Genes with the ability to induce resistance against different types of antimicrobial agents (including antibiotics and disinfectants) could also possibly be regarded as potential BW-agents. It cannot be excluded that new BW-agents (e.g., combinations between existing viruses or combinations between viruses and other genes) could be constructed with this technique..."
TABLE 1: States parties' contributions to the background paper on scientific and technological developments.

\begin{tabular}{|c|c|c|c|c|c|c|c|}
\hline State & $1 s t$ & 2nd & $3 r d$ & 4 th & 5 th & 6th & Total \\
\hline Party & $\mathrm{RC}$ & $\mathrm{RC}$ & $\mathrm{RC}$ & $\mathrm{RC}$ & $\mathrm{RC}$ & $\mathrm{RC}$ & \\
\hline USSR/Russia & $\sqrt{ }^{*}$ & & & & & $\sqrt{ }$ & 2 \\
\hline USA & $\sqrt{ }^{*}$ & & $\sqrt{ }$ & $\sqrt{ }$ & $\sqrt{ }$ & $\sqrt{ }$ & 5 \\
\hline UK & $\sqrt{ }^{*}$ & $\sqrt{ }$ & $\sqrt{ }$ & $\sqrt{ }$ & $\sqrt{ }$ & $\sqrt{ }$ & 6 \\
\hline Hungary & $\sqrt{ }$ & & & & & & 1 \\
\hline Sweden & $\sqrt{ }$ & $\sqrt{ }$ & $\sqrt{ }$ & & $\sqrt{ }$ & $\sqrt{ }$ & 5 \\
\hline Czechoslovakia & & $\sqrt{ }$ & $\sqrt{ }$ & & & & 2 \\
\hline Denmark & & $\sqrt{ }$ & $\sqrt{ }$ & & & & 2 \\
\hline Australia & & & $\sqrt{ }$ & & & $\sqrt{ }$ & 2 \\
\hline Canada & & & $\sqrt{ }$ & & & & 1 \\
\hline Cuba & & & & $\sqrt{ }$ & & & 1 \\
\hline Finland & & & & $\sqrt{ }$ & & & 1 \\
\hline Switzerland & & & & $\sqrt{ }$ & & & 1 \\
\hline Bulgaria & & & & & $\sqrt{ }$ & & 1 \\
\hline South Africa & & & & & $\sqrt{ }$ & & 1 \\
\hline Argentina & & & & & & $\sqrt{ }$ & 1 \\
\hline Czech Republic & & & & & & $\sqrt{ }$ & 1 \\
\hline Netherlands & & & & & & $\sqrt{ }$ & 1 \\
\hline Portugal & & & & & & $\sqrt{ }$ & 1 \\
\hline Secretariat & & & & & & $\sqrt{ }$ & 1 \\
\hline Total & 3 & 4 & 7 & 5 & 5 & 10 & 36 \\
\hline
\end{tabular}

* Joint submission by the three Depositary States.

As is clear from the contributions made by various States Parties to the scientific and technological developments background papers for the following the five-year Review Conferences of 1986, 1991, 1996, and 2006, these and other such possibilities have come to fruition and led to the statements in Final Declarations relating to Article I expressing both clearer appreciations and more apprehensions than were expressed in 1980.

The Final Declaration of the Sixth Review Conference in 2006 had four paragraphs related to Article I. The first two paragraphs stressed the comprehensive coverage of science and technology as follows:

“(1) The Conference reaffirms the importance of Article I, as it defines the scope of the Convention. The Conference declares that the Convention is comprehensive in its scope and that all naturally or artificially created or altered microbial and other biological agents and toxins, as well as their components, regardless of their origin and method of production and whether they affect humans, animals or plants, of types and in quantities that have no justification for prophylactic, protective or other peaceful purposes, are unequivocally covered by Article I.

(2) The Conference reaffirms that Article I applies to all scientific and technological developments in the life sciences and in other fields of science relevant to the Convention." 
TABLE 2: Topics covered in the main body of the UK's contribution to the 2001 Background Paper*.

Genomics and proteomics

Bioinformatics

Human Genome Project and human diversity

Gene therapy

Virulence and pathogenicity

Vaccines and novel therapies

Recombinant protein expression

Toxins and other bioactive molecules

Detection and identification technologies

Human infectious disease patterns

Smallpox destruction

Drug resistance

Disease in agriculture

Pest control in agriculture

Global initiatives to tackle disease

Molecular biology applications and crops

Trends in protein production technologies

International cooperation and biosafety: activities under the Biodiversity Convention

Means of delivery of agents and toxins

Use of pathogens to control weeds and "criminal" crops

Bioremediation: the destruction of material

Countering the threat of BW terrorism

Impact of the entry into force of the CWC

*From [4].

It should also be understood that the word "toxin" here has a much wider meaning than would normally be understood by a biologist. As explained in the 2004 World Health Organization guidance [3], "toxin" here includes midspectrum agents such as bioregulatory chemicals like neurotransmitters, hormones, and cytokines of the nervous, endocrine, and immune systems. There is thus an overlap of coverage for such midspectrum agents as they are clearly also covered by the Chemical Weapons Convention (CWC).

An idea of the range of scientific and technological developments topics considered relevant by States Parties can be gained from a listing of the sections of the main body of the exceptionally large contribution made by the UK in 2001 (Table 2).

Some of the subjects considered-for example, improved detection and treatment capabilities-would be beneficial to the maintenance of the prohibition, but clearly many of the developments could increase the possibilities of misuse. This detailed review by the UK was an annex to a short introductory section which summarised the main bearing of the detailed review. In this regard, the final paragraph of the introduction is of particular importance for the further discussion that I wish to return to at the end of this paper. The UK's introduction ended as follows:

"Throughout the various studies and consultations carried out by the UK to inform this review, it has been clear that the rate of change in science and technology fields relevant to the BTWC has been much greater than in the previous five year period, that is between the third and fourth Review Conferences.... Given the accelerating pace in science and technology, the UK wonders whether it is prudent to maintain a five year gap between such assessments under the BTWC..."

The paragraph went on to state:

"... The UK suggests that the upcoming Review Conference consider establishing a mechanism for States Parties to work together on a more frequent basis to conduct such scientific and technical reviews and to consider any implications at the necessary level of expertise."

This idea, along with much else, was lost in the catastrophic Fifth Review Conference of 2001-2, but it is important to note that the UK's contribution for the 2006 Sixth Review Conference reiterated the point:

"... given the accelerating pace of developments in science and technology in general, the UK continues to hold the view, as expressed in its paper for the Fifth Review Conference, that the Review Conference should consider a process of more frequent, perhaps annual, assessments of scientific and technological developments relevant to the BTWC."

Again nothing came of this idea at the 2006 Review Conference, but perhaps development of the current Intersessional Process (ISP) will allow some such review mechanism to be implemented at the Seventh Review Conference in 2011, for it seems to me that the scope and pace of change in relevant science and technology has certainly not slackened. Indeed, I think that if we are not very careful, scientific and technological advances could threaten the whole chemical and biological prohibition regime.

\section{Neuropeptides}

In order to substantiate such a claim it is necessary to go beyond general surveys and statements and to look in more detail at particular fields of relevant science and technology in order to show that there is a real threat to the regime. Much of the debate about biological weapons since the turn of the century has taken place in the United States and has focused on the possibility that benignly intended civil science and technology might produce materials, technologies, and knowledge that could later be misused by others in acts of bioterrorism. The presentthreat of bioterrorism has been 
wildly exaggerated, but several reports by the US National Academies have served to alert the scientific community to the dangers. The first report, by a committee headed by Gerald Fink, suggested that there were some seven classes of experiments with pathogens that were of sufficient concern to warrant review on the grounds of biosecurity before they were carried out and recommended that a national body be set up to oversee the development of such an oversight system. The US National Science Advisory Board for Biosecurity (NSABB) has struggled in a commendably open manner with this task for several years following its foundation by the Bush Administration. A second report, by the Lemon-Relman committee, greatly widened the range of concerns, suggesting in its Recommendation $2 \mathrm{~b}$ that it was necessary to $[5]$ :

\begin{abstract}
"Adopt a broadened awareness of threats beyond the classical "select agents" and other pathogenic organisms and toxins, so as to include, for example, approaches for disrupting host homeostatic and defense systems and for creating synthetic organisms."
\end{abstract}

Host homeostatic systems are controlled by midspectrum bioregulators such as hormones and neurotransmitters and the defense system is controlled by the cytokines of the immune system.

The Lemon-Relman committee's official title was the Committee on Advances in Technology and the Prevention of their Application to Next Generation Biowarfare Threats. Of course, one reaction to their report might well be that there is always a long gap between the publication of scientific papers and the actual implementation of their findings in ways that affect the real world. In that view, we do not need to get overexcited by the committee's concern about midspectrum agents. However, that would be to ignore the background papers on science and technology developments relevant to the BTWC. For example, the Canadian contribution to the background paper in 1991 stated:

\begin{abstract}
"Canada is pleased to provide the document entitled "Novel Toxins and Bioregulators: the Emerging Scientific and Technological Issues Relating to Verification and the Biological and Toxin Weapons Convention"'”
\end{abstract}

The document itself [6] is 56 pages long and discusses a wide range of novel toxins and bioregulators as set out in Table 3 .

The endorphins and enkephalins, for example, elicit morphine-like effects and these can be reversed by the opiate antagonist naxolone, while oxytocin and vasopressin have functions in a wide range of behaviours such as reproduction and social attachment.

The contribution of the United States for the 1991 background document was confined to the official paper, but it contained a remarkable section on the dangers created by
Table 3: Novel toxins and bioregulators discussed in the Canadian Document for the 1991 Third Review Conference*.

Conotoxins
Sarafotoxin-Endothelin
Bioregulators
Substance P
Thyroliberin (TRF)
Gonadoliberin (LRF)
Somatostatin (SS)
Neurotensin (NT)
Bombesin (BN)
Endorphins and Enkephalins
Dynorphin
Ocytocin and Vasopressin
Other Peptides
*From Section 3 of [6].

the increasing understanding of the role of peptides in living organisms. The section began by defining peptides:

“... peptides are precursors of proteins made up of amino acids. They are interesting molecules for many reasons. They are active at very low concentrations (one part per billion or trillion) which makes their detection very difficult. They can be successfully modified as agonists (more active products) or antagonists (having a contrary activity)..."

It then turned to their functions:

"Their range of activity covers the entire living system, from mental processes (e.g., endorphins) to many aspects of health such as control of mood, consciousness, temperature control, sleep, or emotions, exerting regulatory effects on the body..."

and to the dangers of misuse:

“... Even a small imbalance in these natural substances could have serious consequences, inducing fear, fatigue, depression or incapacitation. These substances would be extremely difficult to detect but could cause serious consequences or even death if used improperly..."

So, whilst it is certainly true that advances in genetic engineering technology allowed a much better understanding of many new peptides (neuropeptides) that function within the brain during the 1990s, the dangers in the potential misuse of this new knowledge were clearly understood by States Parties to the BTWC at the start of that decade.

\section{Advances in Neuroscience}

It is against that background that we must view the very rapid advances in neuroscience at the present time. There 
TABLE 4: Examples of concerns about the future of neuropsychopharmacology*.

\section{- Use of neuropsychological agents as incapacitants}

"Aerosols of opioids serve as excellent incapacitants.... Russia deployed this technology in the Moscow Dubrovka Theatre in 2002. The agents were probably fentanyl derivatives..."

- Nanotechnologies... that allow dispersal of highly potent chemicals over wide areas

"Pharmacological agents are not used as weapons of mass effect, because their large-scale deployment is impractical.... However, technologies that could be available in the next 20 years would allow dispersal of agents in delivery vehicles that would be analogous to a pharmacological cluster bomb or land mine."

- Technologies for highly potent blood-pressure agents or sensory specific pharmacological targeting

"Existing pharmacological agents could be used in a nefarious way.... currently used agents, such as alpha blockers, that would work quickly to drop blood pressure if delivered in high doses.... anticholinergic agents could cause molecular changes that lead to temporary blindness."

\section{- Drug-delivery systems applied to the blood-brain barrier}

"New nanotechnologies have allowed molecular conjugation or encapsulation that may permit unprecedented access to the brain."

*From [8].

can be little doubt about the potential for misuse of advances in this field. A third report by the US National Academies was prepared by a Committee on Military and Intelligence Methodology for Emergent Neurophysiological and Cognitive/Neural Science Research in the Next Two Decades and was titled Emerging Cognitive Neuroscience and Related Technologies [7]. The chair of the committee is on record as stating [8]:

“...The very notion of international agreements leads to an implicit belief that traditional arms control approaches could be relevant to this domain, when in fact, they are irrelevant. The pace of development of the technical areas-neuropharmacology, neuroimaging, and brain-machine interactions... will outpace the hysteresis of the ponderous and arcane processes of traditional security control and disarmament."

The report itself gives several examples of developments that could be of concern (Table 4).

It is possible that nonspecialists may view such concerns about the rate of change in neuroscience research and the possibilities of misuse as somewhat overstated. It is therefore useful to examine the views of a distinguished neuroscientist and very successful communicator of this research field to a wider audience, Professor Steven Ross. He prepared a paper entitled Prospects and Perils of the New Brain Sciences: A Twenty Year Timescale [9] for a meeting at the UK Royal Society in the autumn of 2009. The section and subsections
Table 5: Sections and sub-sections of Prospects and Perils*.

(1) Introduction

(2) The current state of the neurosciences

(a) The new technologies and their potential

(b) The intellectual landscape

(3) Specific prospects

(c) New psychopharmaceuticals and pharmacogenetics

(d) Cognitive enhancers

(e) The neuroscience of social control

(h) New military technologies

(4) Ethical, legal and social issues and initiatives

(5) "Free will" in a neurocentric age

(6) Critical themes for the next twenty years

*From [9].

in Professor Rose's paper are set out in Table 5 and some are clearly of particular interest here.

Whilst it is not possible to summarise the whole of this 48-page paper here, I think it is possible to highlight some of the points that should give pause for thought to anyone imagining that we have time on our hands in regard to the threats posed to the chemical and biological weapons prohibition regime. In this regard, it is necessary to understand that Professor Rose is quite sceptical about some of the overhyped claims of what the current advances in neuroscience may produce in our understanding of the brain and our ability to manipulate it for good or ill. So, what we are dealing with is a determinedly conservative estimate of these advances and their potential impact on society.

Despite such reservations, there is no doubt that significant advances have been made and will continue to be made. As an indicator of the efforts now going into this field, Rose notes:

“...Some 30,000 neuroscientists meet each year at the annual jamboree of the American Neuroscience Association, 6000 at the biennial meetings of the Federation of European Neurosciences. In the US, the NIH entitled the 1990s the Decade of the Brain, whilst the current decade has less formally become known as the Decade of the Mind..."

What is clear is that a previously rather diverse set of approaches to studying the brain and behaviour-anatomy, physiology, genetics, psychology, and information scienceshave increasingly been brought together in a more united effort. As Rose points out, the name of this fieldneuroscience-provides an overarching label within which the different fields can fit. In his opinion, neuroscience is certainly one of the fastest growing fields within the whole of the life sciences and it is characterised by the importance, for its own advances, of a new range of technologies and advances in other sciences. The most powerful of these supporting technologies, in Rose's opinion, include brain imaging, smart pharmacological agents, and mice with specific genes inserted or removed (see Table 6). 
Most people will have seen images taken with the various techniques which show activity in the brain when specific tasks are being undertaken. Rose notes the serious difficulties there are in interpreting exactly what these images mean, but these imaging techniques certainly have been a major advance in linking anatomy and physiology of the central nervous system. Less well known is single photon confocal microscopy. Rose's description of this gives an indication of the level of sophistication becoming available to neuroscientists today:

"... Neurons maintained in tissue slices or in cell culture can be loaded with light sensitive dyes that respond to the flow of ions such as calcium into specific regions of the cell in response to electrical or pharmacological signals..."

He points out that this flow can be tracked and "for the biochemical mechanisms of such cellular responses to be studied even at the scale of a single synapse."

It is striking that in his subsection on "smart pharmacology" Rose states:

"It is above all in the context of pharmacological research that classical neurophysiology begins to intersect with the new cellular, molecular and even genetic sciences..."

Transmission of information within single neurons is electrical but transmission between neurons is overwhelmingly by chemical means: specific receptors are affected by released neurotransmitters or circulating neuromodulators. As he points out, almost all psychoactive drugs act by affecting these chemical transmission systems. The genomic revolution built on this understanding by allowing many more neuropeptides to be discovered and the nature of the many neuroreceptors and receptor subtypes to be described. Thus:

“... Genetic and protein sequencing techniques enable the structures of individual receptors to be determined, and thus make it possible for pharmaceutical companies to engage in the rational synthesis of molecules designed to interact precisely with specific receptors ("smart" drugs)..."

This, or course, is a step change in capabilities from the development of older drugs which had much more general effects.

Combined with such advances has been the development of capabilities to "knock in" or "knock out" specific genes. As Rose notes:

“... Indeed mice with almost any specific gene modification requested by the researcher can now be purchased off the shelf from specialist companies..."

There are complications, of course, in trying to understand the impact of such modifications as compensatory adjustments may be made during the animal's development. Now,
TABLE 6: Some powerful technologies supporting work in neuroscience*.

(a) Advances in direct imaging of the living brain through functional magnetic resonance imaging... and related techniques...

(b) "Smart" pharmacological agents and dynamic imaging systems such as single photon confocal microscopy.

(c) Mice with specific inserted ("knocked in") or deleted ("knocked out") genes and other "gene-silencing" procedures, providing animal models for human behavioural and neurological deficits.

(d) Increased knowledge of the human genome.

*From [9].

however, new techniques allow a gene to be temporarily silenced in a specific brain region of an adult animal. This is a rapidly developing area of research and:

“... Combined with molecular pharmacology and cellular physiology, it offers the prospect of sharper insights into regional localisation, synaptic function and the molecular systems underlying behaviour..."

Together, these are powerful capabilities that are bound to improve our understanding of specific behaviours in coming decades.

Rose, however, in his survey of the intellectual landscape, argues that despite this rich cornucopia of data, the field of neuroscience is "theory poor." In his view, the different disciplines that have now started to come together have a long way to go before they have an integrated approach that might allow an understanding of complex issues such as the nature of consciousness. Nevertheless, progress is being made, for example in our understanding of how important emotions are in cognition. This more biologically based understanding is, in Rose's opinion, replacing the older idea of the brain being some kind of cognitive machine divorced from the body.

Another sign of the integration of more biologically based thinking has come from the realisation that there are very few more genes in humans than in other species:

“...What distinguishes humans from chimpanzees occurs during development, and the ways in which the expression of these genesthat is, their utilisation by particular cells at particular times in the synthesis of proteins - is regulated..."

Thus development is:

"... shaped both on environmental contingencies and the actions of a relatively small number of regulatory genes-genes that control the expression of others..."

Rose stresses that the role of these regulatory genes has now come under intense investigation and has led to much greater emphasis on brain plasticity, and how it changes in response 
to experience. As he comments, "( $t$ )he importance of such a developmental perspective to the understanding of the adult, long understood by child psychiatrists, is increasingly coming to the attention of neuroscientists as well."

"Social" neuroscience seems an odd topic at first sight. As Rose explains, the finding that apes and humans have neurons in the brain that are active both when a person or ape performs a particular action and when others are observed performing a similar action ("mirror" neurons) again led neuroscientists to the biological fact that we social animals! This has quickly led onto the new field of social neuroscience in which "brain events involved in recognising and responding to others' feelings and emotions" has come under scrutiny.

In regard to the specific prospects of useful materials, technologies, and knowledge arising from all the research, Rose might be described as an optimistic pessimist. He sees many more difficulties than one might imagine from the news headlines, but also thinks there are ways forward that could produce usable results in the 20 year timescale he was considering. So, while he thinks the idea of drugs being developed to fit each individual's unique genome will not be economically possible:

"... The economic and health benefits of at least a broad screening of individuals for relevant genetic markers... before prescribing in conditions such as depression are likely to be considerable, despite the well known problems of false positives and negatives associated with such screening."

Similarly, he does not think any cognitive enhancers have lived up to their promise to date, but:

"... as research in this field is moving rapidly it is highly likely that effective agents will become available over the coming decade, if only as a spin-off from $\mathrm{AD}$ (Alzheimer's Disease) research..."

Clearly, if this "highly likely" outcome results, Rose also points out that it will cause ethical, legal, and social issues for society.

Another debate is likely to arise from other research work on memory and memory loss. It has been found that:

“... Laboratory animals, trained on a specific task, can be made to forget if they are presented once more with the task situation and given drugs that block glutamate drugs..."

This has led to the suggestion that people suffering from post traumatic stress disorder could be helped by such methods and much work in academic and biotech laboratories.

Given the continuing indeterminacy of the diagnosis of mental illnesses, Rose clearly has considerable concerns over neuroscience being used forsocial control. As he writes:
"...What is clear is that we are moving into a world in which psychopharmacological adjustment of an individual's behaviour to fit within prescribed norms is becoming common and can only become increasingly so with advances in the sophistication of the available pharmaceuticals."

Yet, in addition to all of the other questions that such procedures pose, we have little idea of the long-term effects of routine use of such psychoactive drugs.

Professor Rose also has concerns about military interest in some of these developments. He notes that US interest in the use of LSD and other drugs has been well documented for the Cold War period. However, he states:

"...Less well known has been the scale of research in the US, Europe and Russia, on new generations of "non-lethal" agents.... The intended function of these substances is to produce temporary incapacitation by affecting sensory or motor systems but without lasting adverse effects..."

and points out that the developments come to the attention of the general public in 2002 with "the disastrous attempt by Russian special forces to release hostages held in a Moscow theatre." I shall return to this issue at the end of the paper, but first I wish to give a specific illustration of how advances in neuroscience could facilitate effective misuse.

\section{Sniffing Neuropeptides}

One of the most startling examples of the rate of change in neuroscience research concerns the sleep disorder, narcolepsy. This very disabling condition involves considerable disruption of sleep, and in particular, instances of catalepsy in which muscle tone is suddenly lost. Little was understood about the cause of this condition until the late 1990s although it was clear that some dogs suffered from inherited (i.e., genetically caused) narcolepsy. Then, in the late 1990s, two research groups announced that they had discovered two new neuropeptides in the brain. These have been named orexins (or hypocretins). It rapidly became clear that disruption of the production of these neuropeptides or the receptors for them was the cause of narcolepsy. Although in humans inherited narcolepsy is very rare, most people suffering from the condition lack these neuropeptides-it is thought because of an autoimmune condition. The orexins appear to be important because they stabilise the waking condition and in their absence the waking and sleeping systems become unstable. Clearly, if it were possible to interfere with the function of the orexins then there would be available to those with malign intent an impressive means of incapacitation.

This becomes of interest because of recent work on one of the earliest known of the neuropeptides. Oxytocin has long been known to be involved in the regulation of aspects of reproductive and social attachment behaviour. It was discussed, for instance, in the 1991 Canadian paper mentioned 
earlier. In 2005, Nature carried a paper on a game played by two human subjects which showed quite clearly that a dose of oxytocin given through the nose (intranasal delivery) considerably increased the trust shown by the person who had received the oxytocin. Not surprisingly, this caused a great deal of interest and led to much follow-on work. For example, it was shown that oxytocin delivered via this route significantly reduced the activation of the amygdala response to the viewing of threatening faces. The amygdala, of course, is crucial to the processing of responses to threat. It has also been shown more recently that oxytocin's impact on the person's behaviour in the original game persists even if their trust has been breached several times by the other player [10].

The way that drugs pass from the nose to the brain is not yet entirely clear and may well vary for different drugs. Transport of the oxytocin along the olfactory nerves from the sensory endings in the nose direct to the brain is a possibility, but too slow for the rapid effects seen. The nose also has multiple blood vessels and passage through the blood to the brain is also possible. A different possibility arises because, unlike other neurons, the olfactory receptor neurons-which are regularly in contact with environmental toxins-are regenerated about every 3-4 weeks. Furthermore, the special olfactory ensheathing cells that surround the axons of the olfactory receptor cells stay in place so the new olfactory receptor neurons can pass through them. As this regeneration process is always going on for some olfactory receptor neurons the nasal barriers to entry into the brain could well be much more "leaky" than elsewhere, where the blood-brain barrier affords greater protection against the entry of potentially psychoactive chemicals. From the perspective of this paper, what is crucial to understand is that there are many ways in which the efficiency of delivery via the intranasal route might be increased. These include encapsulation of the drug so that it is more soluble at the nasal epithelium, the addition of vasoconstrictors to the aerosol to reduce clearance of the drug, or the use of nanoparticles that have ligands to bind to the epithelial cell surface to carry the drug [11].

This route of delivery has also been shown to be effective in altering the sleep system of primates. Animals that had been deprived of sleep and were performing badly on a cognitive task were shown to improve if given intravenous or intranasal orexin. Significantly, the investigators reported that [12]:

"... delivery of orexin-A via the nasal route was...more potent because the nasal spray... was only...1/10 of the most effective i.v. dose."

Since orexin antagonists are also known to affect the sleep cycle in man (i.e., by enhancing the sleep system rather than the waking system), the malign possibilities for incapacitation by this route are obvious (see Table 4, second item).

\section{Maintaining the Prohibition?}

Given the wording of Article I of the BTWC and the agreed statements at successive Five-Year Review Conferences, particularly in 2006, it may be asked what reason there is to be concerned about scientific and technological developments threatening the future of the BTWC. First, of course, as Robinson has cogently argued [13], in present and likely future wars "amongst the people" chemical and biological weapons could seem particularly attractive to some of the participants and thus there could be an erosion of the prohibition by actions taken on the ground. The fact that developments in the life and associated sciences might well make the development of effective chemical and biological weapons easier and more accessible to substate groups could clearly accelerate a degenerative process if it got underway.

A more immediate threat, it seems to me, comes from the interest that developed states have shown, as Professor Rose noted, in the potential use of new forms of so-called "nonlethal" chemical weapons. Clearly, there is a major question as to why incapacitating chemicals should be called "nonlethal" weapons when the difficulties of controlling air concentrations after dispersal and differential responses to any given dose make it unlikely there will not be deaths if such agents are used on a large scale, as happened in the 2002 Moscow theatre siege. Nevertheless, as chemistry and biology become increasingly indistinguishable and the CWC and BTWC overlap in their coverage of midspectrum agents such as bioregulators, a threat to the CWC could obviously impact on the BTWC.

Though the CWC was negotiated twenty years later than the BTWC and is generally regarded as being much stronger, there is a potentially damaging loophole at the heart of the CWC. This is caused by one of the peaceful purposes being stated in Article II.9 (d) as [14]:

"Law enforcement including domestic riot control purposes."

Clearly, on a natural reading of that sentence law enforcement is a wider category than domestic riot control and therefore there could be law enforcement chemicals other than domestic riot control agents. As law enforcement is not defined in the CWC, some people might well argue that novel law enforcement incapacitating chemicals (like fentanyl derivatives) could be legally used in various situations. Should that become evidenced in further state practice, it is difficult to see where the process of development of new incapacitants might end.

It can be argued that as there is no such exemption for law enforcement in the BTWC, the best approach is to "let sleeping dogs lie" and not raise the issue of the so-called nonlethal agents in regard to the BTWC. A danger then is that if State Practice develops so as to erode the prohibition in regard to the CWC, would not the argument then be made that law enforcement was an equally "peaceful purpose" under the BTWC?

In any event, it does seem that the present five-yearly somewhat ad hoc review system for scientific and technological developments relevant to the BTWC needs itself to be carefully reviewed and other possibilities considered at the Seventh Review Conference in 2011. There is, of course, a wide range of different mechanisms available in the toolkit of diplomatic negotiators in order to accomplish this task [15]. The CWC, for example, has a Scientific Advisory Board 
and an emergent tradition of receiving a broadly based report from the International Union of Pure and Applied Chemistry (IUPAC) before its Five-Year Review Conferences. However, to have a Scientific Advisory Board suggests that there is an organisation to request and receive reports, and for an NGO to prepare a broadly based five-yearly review suggest that an official of the organisation similarly has to request and receive the report. Given the history of the "institutional deficit" of the BTWC and the long-term difficulties of correcting that deficit, it seems unlikely that such mechanisms could be agreed for the BTWC in 2011.

A more likely step forward might be for the present annual meetings to become more systematic, including regular agenda items such as a review of relevant scientific and technological developments and perhaps backup by a scientific advisory panel associated with a strengthened secretariat [16]. The question then is how can practicing neuroscientists be engaged in providing their expertise in order to help protect their benignly intended work from misuse? That, in my opinion, will require an expansion of their awareness of the responsibilities they bear for these potentially bad as well as the good societal impacts of their work [17].

\section{Acknowledgment}

This paper was presented at a meeting organised by the University of Bath and UNIDIR, "The Global Challenge of Biological Controls," at the Palais des Nations, Geneva, 8-9 April, 2010.

\section{References}

[1] The text of the Convention, http://www.opbw.org/.

[2] The text of the Final Declarations, http://www.opbw.org/.

[3] World Health Organization, Public Health Response to Biological and Chemical Weapons: WHO Guidance, WHO, Geneva, Switzerland, 2004.

[4] Secretariat, "Background Paper on New Scientific and Technological Developments Relevant to the Convention on the Prohibition of the Development, Production and Stockpiling of Bacteriological (Biological) and Toxin Weapons and on their Destruction," BWC/CONF.V/4/Add. 1. United Nations, Geneva, Switzerland, October 2001.

[5] Committee on Advances in Technology and the Prevention of their Application to Next Generation Biowarfare Threats, Globalization, Biosecurity and the Future of the Life Sciences, National Academies Press, Washington, DC, USA, 2006.

[6] The further information provided in slide 8 of Lecture 17 of the Education Module Resource, http://www.dual-usebioethics.net/.

[7] Committee on Military and Intellgence Methodology for Emergent Neurophysiological and Cognitive/Neural Science Research in the Next Two Decades, Emerging Cognitive Neuroscience and Related Technologies, National Academies Press, Washington, DC, USA, 2008.

[8] C. Green, "The potential impact of neuroscience research is greater than previously thought," Round Table, Bulletin of the Atomic Scientists, 2008.

[9] S. P. R. Rose, Prospects and Perils of the New Brain Sciences: A Twenty Year Timescale, Royal Society 'Neuropolicy Lab'. Royal Society, London, UK, 2009.
[10] T. Baumgartner, M. Heinrichs, A. Vonlanthen, U. Fischbacher, and E. Fehr, "Oxytocin shapes the neural circuitry of trust and trust adaptation in humans," Neuron, vol. 58, no. 4, pp. 639650, 2008.

[11] S. V. Dhuria, L. R. Hanson, and W. H. Frey II, "Intranasal delivery to the central nervous system: mechanisms and experimental considerations," Journal of Pharmaceutical Sciences, vol. 99, no. 4, pp. 1654-1673, 2010.

[12] S. A. Deadwyler, L. Porrino, J. M. Siegel, and R. E. Hampson, "Systemic and nasal delivery of orexin-A (hypocretin1) reduces the effects of sleep deprivation on cognitive performance in nonhuman primates," Journal of Neuroscience, vol. 27, no. 52, pp. 14239-14247, 2007.

[13] J. P. P. Robinson, "Difficulties facing the chemical weapons convention," International Affairs, vol. 84, no. 2, pp. 223-239, 2008.

[14] M. Crowley, "Dangerous ambiguities: regulation of riot control agents and incapacitants under the chemical weapons convention," Bradford Non-Lethal Weapons Research Project Report, October 2009, http://www.dual-usebioethics.net/.

[15] C. Rhodes and M. R. Dando, "Options for a scientific advisory panel for the biological weapons convention," in The Web of Prevention: Biological Weapons, Life Sciences, and the Governance of Research, B. Rappert and C. McLeish, Eds., pp. 95-114, Earthscan, London, UK, 2007.

[16] N. Sims, "Next step in remedying the institutional deficit," in Proceedings of the 30th Workshop of the Pugwash Study Group on Implementation of the CBW Conventions: Preparing for the Seventh BWC Review Conference, Geneva, Switzerland, December 2009.

[17] C. Bell, "Neurons for peace. Take the pledge brain scientists," New Scientist, no. 2746, February 2010, http://www.newscientist.com/article/mg20527465.900-neurons-for-peace-takethe-pledge-brain-scientists.html. 

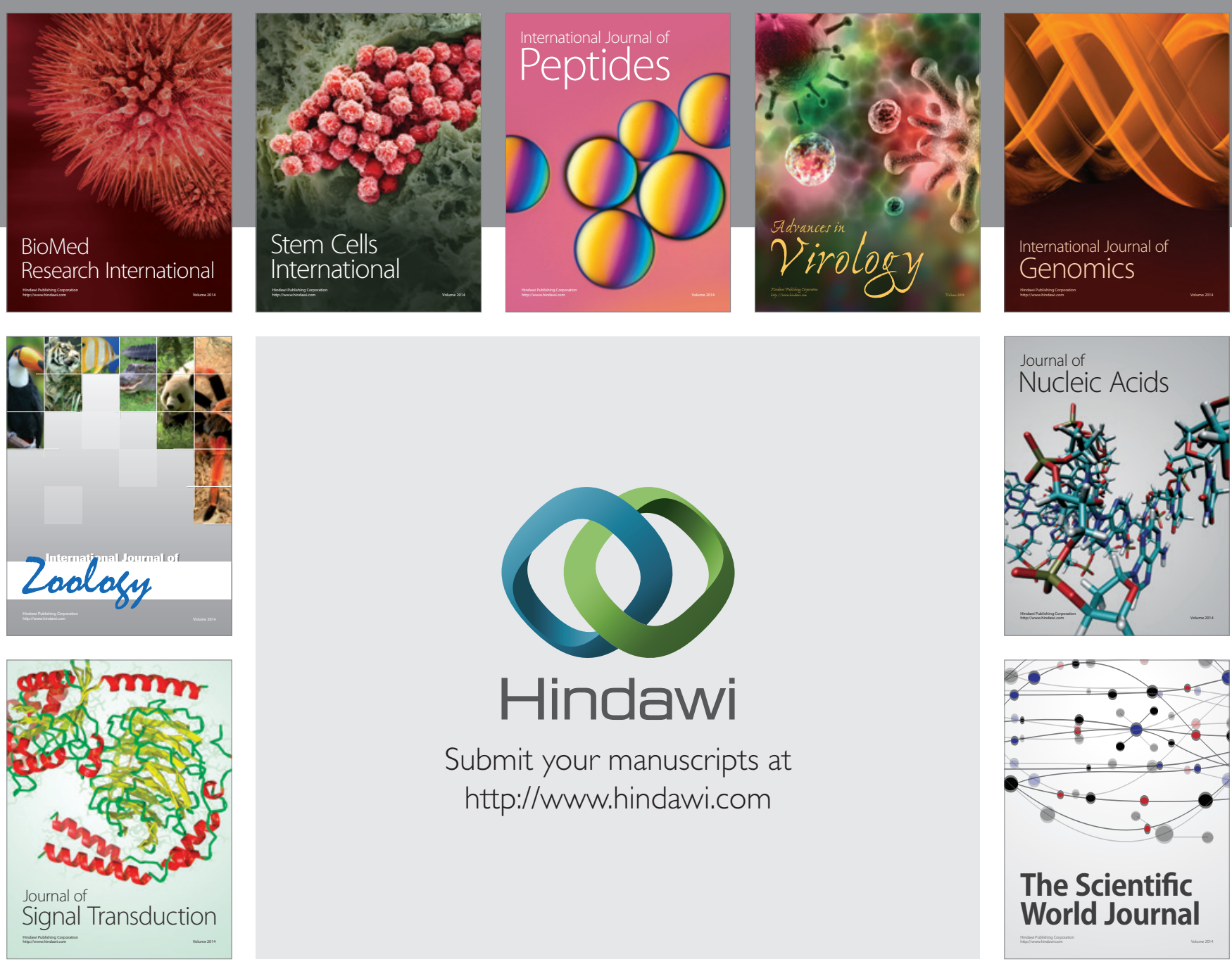

Submit your manuscripts at

http://www.hindawi.com
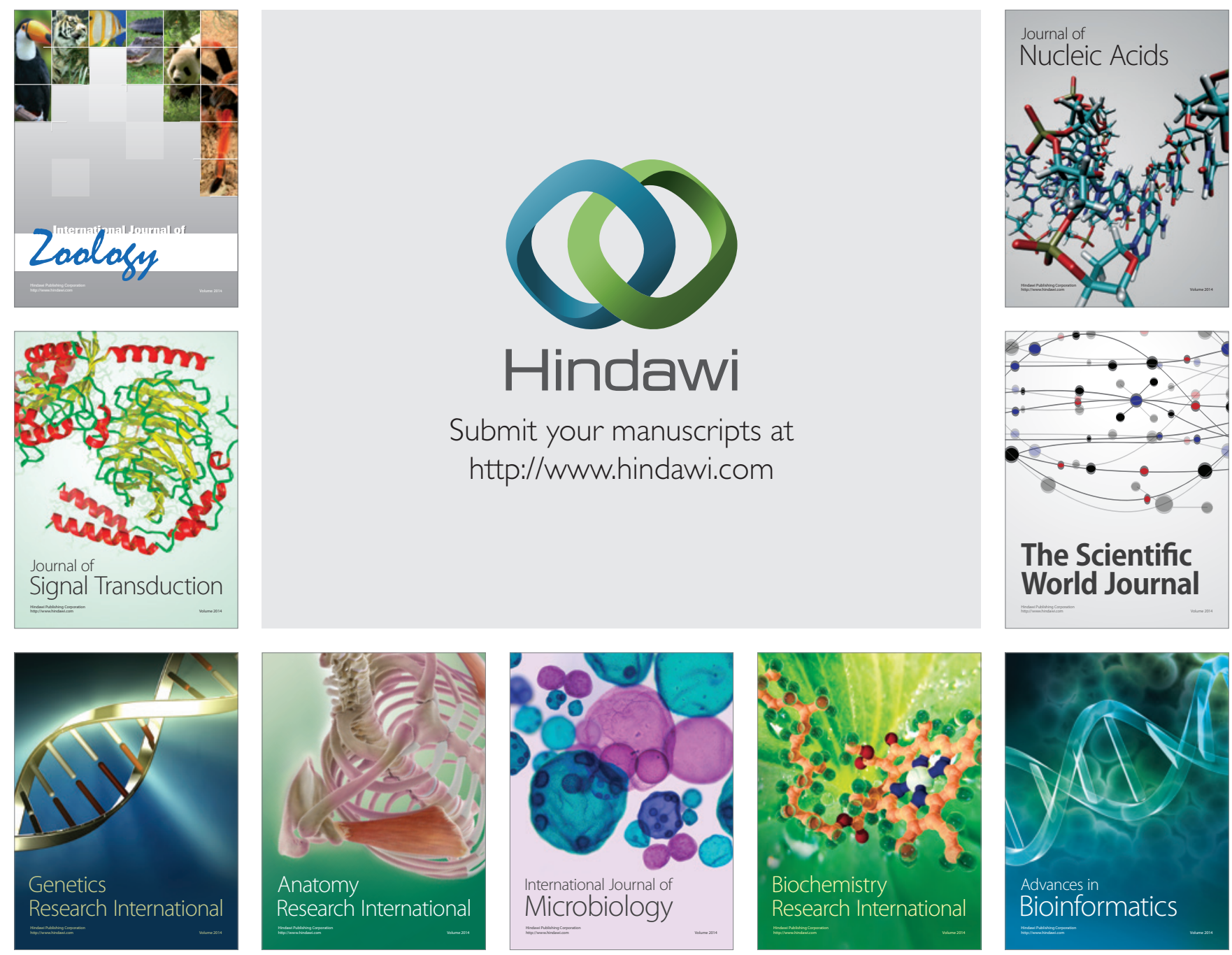

The Scientific World Journal
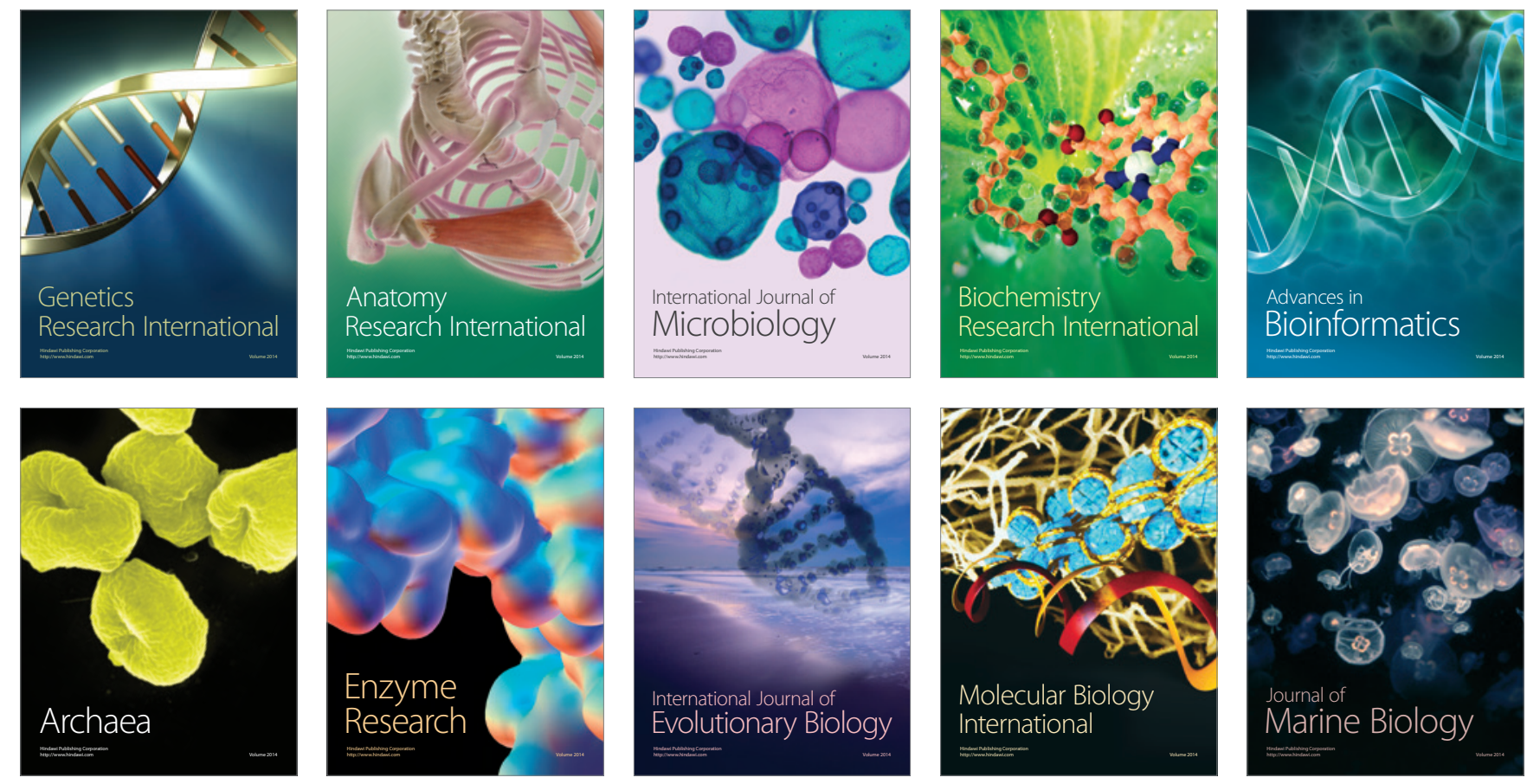